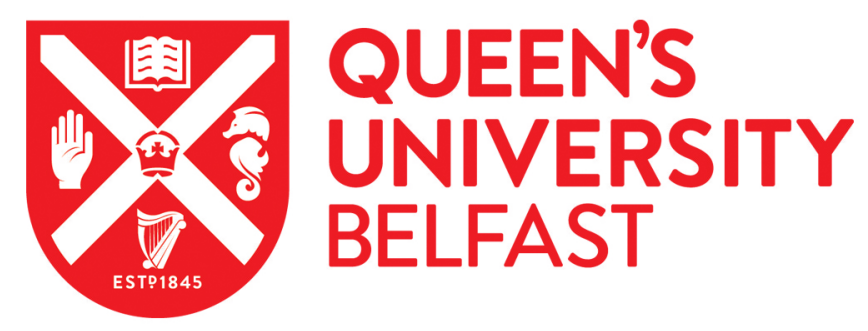

\title{
Regio- and Stereoselectivity of CYP450BM3-Catalyzed Hydroxylation of Complex Terpenoids: A QM/MM Study
}

Hui, C., Singh, W., Quinn, D., Li, C., Moody, T., \& Huang, M. (2020). Regio- and Stereoselectivity of CYP450BM3-Catalyzed Hydroxylation of Complex Terpenoids: A QM/MM Study. Physical Chemistry Chemical Physics , 22(38), 21696-21706. https://doi.org/10.1039/D0CP03083J

Published in:

Physical Chemistry Chemical Physics

Document Version:

Peer reviewed version

Queen's University Belfast - Research Portal:

Link to publication record in Queen's University Belfast Research Portal

Publisher rights

Copyright 2020 Royal Society of Chemistry. This work is made available online in accordance with the publisher's policies. Please refer to any applicable terms of use of the publisher.

\section{General rights}

Copyright for the publications made accessible via the Queen's University Belfast Research Portal is retained by the author(s) and / or other copyright owners and it is a condition of accessing these publications that users recognise and abide by the legal requirements associated with these rights.

Take down policy

The Research Portal is Queen's institutional repository that provides access to Queen's research output. Every effort has been made to ensure that content in the Research Portal does not infringe any person's rights, or applicable UK laws. If you discover content in the Research Portal that you believe breaches copyright or violates any law, please contact openaccess@qub.ac.uk. 
2 Catalyzed Hydroxylation of Complex Terpenoids: A

\section{QM/MM Study}

4

5

$6{ }^{1}$ Department of Chemistry \& Chemical Engineering, Queen's University, Belfast, BT9 5AG

$7 \quad$ Northern Ireland, United Kingdom

$8{ }^{2}$ Almac Sciences, Department of Biocatalysis and Isotope Chemistry, Almac House, 20

9 Seagoe Industrial Estate, Craigavon BT63 5QD, Northern Ireland, United Kingdom

10

Chenggong Hui ${ }^{1 \neq}$, Warispreet Singh ${ }^{1,2 \neq, \S}$, Derek Quinn ${ }^{2}$, Chun Li, ${ }^{3,4}$ Thomas S. Moody ${ }^{2,5}$, Meilan Huang ${ }^{1 *}$

3 Institute for Synthetic Biosystem/Department of Biochemical Engineering, School of Chemistry and Chemical Engineering, Beijing Institute of Technology, Beijing 100081, P.R. China

${ }^{4}$ Key Lab of Industrial Biocatalysis Ministry of Education, Institute of Biochemical Engineering, Department of Chemical Engineering, Tsinghua University, Beijing, 100084, P. R. China

5 Arran Chemical Company Limited, Unit 1 Monksland Industrial Estate, Athlone, Co. Roscommon, Ireland

Corresponding author: Meilan Huang

m.huang@qub.ac.uk

${ }^{\neq}$These authors contribute equally to the paper

${ }^{\S}$ Current address: Faculty of Health and Life Sciences, Northumbria University, Newcastle upon Tyne, NE1 8ST, England, United Kingdom 
The site-selective $\mathrm{C}-\mathrm{H}$ oxidation of terpenoids by $\mathrm{P} 450$ attracts great attention because of their wide range of biological activities. However, the binding and catalytic mechanism of P450 for hydroxylation of complex terpenoid substrates remains elusive, which has limited the rational engineering of P450 as biocatalysts for terpenoid biosynthesis. Here, we studied the origin of the selectivity and reactivity of $\mathrm{P} 450_{\mathrm{BM}}$ in the hydroxylation of terpenoids by combining molecular dynamics simulations and $\mathrm{QM} / \mathrm{MM}$ calculations, using artemisinin as model compound. We found that the conformational change of the $\beta 1$ sheet at the substrate entrance and the displacement of the $\beta$ ' helix was critical for reshaping the binding pocket to modulate substrate entrance and positioning the $\mathrm{C}-\mathrm{H}$ to be activated toward the oxidative species of $\mathrm{P} 450$ for the subsequent hydrogen abstraction, the rate-determining step of the hydroxylation. There is a distinct linear correlation between the activation barriers and the reaction coordinates, indicating the reaction coordinates can be used as a facile descriptor for predicting the reactivity of $\mathrm{P} 450_{\mathrm{BM}}$. These findings would provide a valuable guidance for predicting the selectivity and reactivity of $\mathrm{P}^{4} 50_{\mathrm{BM} 3}$ for selective hydroxylation of non-native terpenoid substrates so as to prioritize the rationally designed enzymes for terpenoid biosynthesis. 


\section{INTRODUCTION}

The cytochrome P450 is a superfamily of heme-containing mono-oxygenases that can catalyze a broad range of chemical reactivity such as hydroxylation, dealkylation, sulfoxidation and even unusual cyclization. ${ }^{1,2}$ It can catalyze site-selective oxidation of $\mathrm{C}-\mathrm{H}$ bond in terpenoids that are generally not accessible by traditional metal catalysis with high regio- and stereoselectivity, due to the different electronic and steric properties of the $\mathrm{C}-\mathrm{H}$ bonds in the molecules. $^{3-7}$ Of particular importance is the Bacillus megaterium $\mathrm{P} 450_{\mathrm{BM} 3}$ (CYP102A1), a catalytically self-sufficient fatty acid monooxygenase that exhibits the highest reported monooxygenase activity among the $\mathrm{P} 450$ family enzymes.

Terpenoids are the most populated natural compounds and their biosynthesis has attracted great interest due to their potential biological activities and therapeutic applications. ${ }^{8,9}$ For example, artemisinin, a sesquiterpene lactone compound, is among the most effective drugs used for the treatment of malaria. Several P450 variants from Bacillus megaterium obtained through directed evolution showed complete regio- and enantioselectivity in the oxidization of artemisinin at $\mathrm{C} 6 \mathrm{a}$ and $\mathrm{C} 7$ positions located at the upper hemisphere of artemisinin molecule. ${ }^{10}$ Despite the outstanding performance of the $\mathrm{P} 450_{\mathrm{BM} 3}$ variants, there is little study on their action mechanisms due to lack of the crystal structure of $\mathrm{P} 450_{\mathrm{BM} 3}$ in complex with a bulky cyclic substrate.

Molecular docking, Molecular dynamics (MD) simulations and quantum mechanics/molecular mechanics $(\mathrm{QM} / \mathrm{MM})$ provide valuable insight into ligand binding and catalytic reactions in the vicinity of active site of enzymes, which can be utilized in structure-based rational protein engineering studies. P450 and its variants have been studied extensively using density functional theory to disclose the information on the catalytic mechanism particularly on the very short-lived reaction intermediates and transition states involved in the catalytic cycle. ${ }^{11}$ 
e.g. Dubey et al studied the origin of the regio- and stereoselectivity in $\mathrm{P} 450_{\mathrm{BM} 3}$ enzyme for the hydroxylation of fatty acid substrate N-palmitoylglycine, which mimics the native substrate, by applying the aforementioned computational methods (Figure 1A). ${ }^{12}$ Ramanan et al successfully implemented MD and QM/MM calculations to understand the origin of fatty acid oxidation at the $\alpha$-position with S-enantioselectivity in P450 SP $\left(\right.$ Figure 1A). ${ }^{13}$

However, to our knowledge, the hydroxylation mechanism of P450 toward a non-native cyclic substrate has not been reported yet. It should be noted that the previously reported selective $\mathrm{P}_{450} \mathrm{BM}_{3}$ variants for terpenoids were usually derived from a template that already contains a number of mutations. In order to rationally and efficiently engineering the enzyme for selective hydroxylation of bulky natural products such as terpenoids, it is necessary to answer the following questions: (i) What is the critical region in the enzyme that would dictate its selectivity in the hydroxylation of non-native cyclic terpenoids? (ii) Is there a quantitative property that can be easily acquired for predicting the reactivity of the enzymes?

Here we studied the hydroxylation of non-native terpenoid substrates using artemisinin as model compound, by performing molecular docking, molecular dynamics simulations and QM/MM calculations. We found that the substrate entrance and binding are dependent on the conformational change of the $\beta 1$ sheet at the substrate entrance and the displacement of the $\beta$, helix which reshaping the binding pocket to accommodate the cyclic substrate. There is a clear linear correlation between the free energy barriers required to activate the $\mathrm{C}-\mathrm{H}$ bonds and reaction coordinates. The information obtained from the study would shed light for the design of selective biocatalysts for directed oxidative functionalization of $\mathrm{C}-\mathrm{H}$ bonds in non-native terpenoid substrates.

\section{METHODS}

\section{Protein preparation}


97 The initial structure of the cytochrome $\mathrm{P} 450_{\mathrm{BM} 3}$ was taken from the crystal structure of Bacillus megaterium $\mathrm{P} 450_{\mathrm{BM} 3}$ (PDB: 1BVY). ${ }^{14}$ The ethylene glycol molecule in the crystal structure was removed and replaced with an oxygen atom. The resulting high-valent-iron (IV)oxo porphyrin- $\pi$-cation-radical active species, commonly known as the compound I (Cpd I), was used in the subsequent docking, $\mathrm{MD}$ and $\mathrm{QM} / \mathrm{MM}$ study. The oxidation reaction of the substrate is initiated from the hexacoordinated Cpd I. It is the main oxidant in the P450 enzyme and performs the rate determining step of the reaction by abstracting hydrogen atom from a C$\mathrm{H}$ bond. The force field parameters of the Cpd I were taken from a recent study. ${ }^{15}$ The missing hydrogen atoms were added using the tleap module implemented in Amber $16 .{ }^{16}$ The parameters for Artemisinin were prepared using the general Amber force field (GAFF) implemented in Antechamber. The atomic charges of the ligand were calculated using restrained electrostatic potential (RESP) method at $\mathrm{HF} / 6-31 \mathrm{G}^{*}$ level of theory using Gaussian16. ${ }^{17}$

\section{Molecular docking}

The ligand was docked to the MD simulated structures of the $\mathrm{P} 450_{\mathrm{BM} 3}$ enzyme or its variants in the close vicinity of Cpd I. Molecular docking was performed using the AutoDock 4.2 suite with the Lamarckian genetic algorithm (LGA) and the standard free energy scoring function. The partial charges for the Cpd I in the docking study were taken from a previous study. ${ }^{15} \mathrm{~A}$ total of 100 LGA runs were carried out for each ligand: protein complex. The population was 300 , the maximum number of generations was 27,000 and the maximum number of energy evaluations was 2,500,000. Flexible docking was run for II-H10, where Phe87 was set as the flexible residue.

\section{MD simulations}


The $\mathrm{P} 450_{\mathrm{BM} 3}$ variants were solvated into a truncated octahedral box with $\mathrm{TIP} \mathrm{P}^{18}$ water molecule such that no protein atom was within $10 \AA$ to any edge of the box. The periodic boundary conditions were employed in all the simulations. The counter ions were added to the protein surface to neutralize the total charge of the system. The Amber FF14SB force field was employed. The systems were subjected to two successive steps of energy minimization first using steepest descent (2,500 steps) and conjugate gradient algorithms (2,500 steps) with protein and ligand restrained with constant of $50 \mathrm{kcal} \mathrm{mol}^{-1} \mathrm{~A}^{-2}$ followed by steepest descent (2,500 steps) and conjugate gradient algorithms (2,500 steps) without restraint. The systems were gradually heated from 0 to $300 \mathrm{~K}$ for 250 ps under the NVT ensemble by restraining the solute molecules using harmonic potential of $50 \mathrm{kcal} \mathrm{mol}^{-1} \AA^{-2}$ using Langevin thermostat ${ }^{19}$ with a collision frequency of $1 \mathrm{ps}^{-1}$. The systems were then subjected to $50 \mathrm{ps}$ of equilibration at $300 \mathrm{~K}$ in the NPT ensemble with a restraint of $5.0 \mathrm{kcal} \mathrm{mol}^{-1} \AA^{-2}$. An additional $1 \mathrm{~ns}$ NPT with a restraint constant of $5.0 \mathrm{kcal} \mathrm{mol}^{-1} \AA^{-2}$ was performed for the IV-H4 and II-H10 mutants prior to the final production MD. The Barendsen barostat ${ }^{20}$ was used to maintain the pressure at 1 bar. A production MD run was performed using the GPU version of PMEMD with Amber 16 in a NPT ensemble with a target pressure of 1 bar and a pressure coupling constant of 2 ps. Eight replicas of MD runs were conducted for each complex, making a total simulation time of 0.8-4.8 $\mu \mathrm{s}$. The SHAKE algorithm ${ }^{21}$ was used to constrain the bonds of all hydrogen atoms. Long-range electrostatic interactions were calculated using the particle mesh Ewald (PME) method $^{22}$ with a direct space and vdW cut-off of $10 \AA$. The trajectories were analysed using pytraj $^{23}$ and $\mathrm{VMD}^{24}$.

\section{QM/MM calculations}

The reaction profiles of $\mathrm{P} 450_{\mathrm{BM} 3}$ variants in the catalysis of artemisinin were studied by using QM/MM calculations implemented in Chemshell. ${ }^{25}$ The QM calculations were performed using ORCA 4.2.0 ${ }^{26}$ and the MM part was defined using DL_POLY. ${ }^{27}$ The effect of the protein 
environment on the polarization of the QM wavefunction was described by the electronic embedding scheme. ${ }^{28}$ The snapshots for the QM/MM calculations were obtained from the equilibrated MD trajectory using cluster analysis. The representative snapshots from cluster analysis were then subsequently subjected to the energy minimization by using steepest descend $(1,250)$ and conjugate gradient $(1,250)$ algorithms using Amber16. ${ }^{16}$ The water shell within $4 \AA$ of the protein or within $20 \AA$ of the $\mathrm{QM}$ atoms were retained. The $\mathrm{QM}$ region consists of the whole Cpd I molecule, Artemisinin and the C400 residue truncated at C $\beta$ positions. For II-H10, in addition to the aforementioned atoms, a benchmark study was conducted with and without Phe87 in the QM region in view of the flexibility of Phe87 observed from the MD simulations. The overall charge of QM region was -2 . The residues which are within $10 \AA$ of Cpd I and artemisinin were allowed to move freely and the rest of the system was frozen during the geometry optimization. The hydrogen link atoms ${ }^{29}$ were used to saturate the dangling bond at the QM/MM boundary.

The reaction coordinate was defined by the distance between the oxygen atom of the $\mathrm{Fe}(\mathrm{IV})=\mathrm{O}$ in Cpd I and the hydrogen atom to be abstracted. The transition state (TS) structures were obtained by potential energy scan followed by dimer TS search implemented in DL-FIND ${ }^{30}$, and were subsequently validated by frequency calculation. Only one imaginary frequency corresponding to the hydrogen transfer was showed. All QM calculations were performed with DFT using UB3LYP ${ }^{31,32}$ with D3 dispersion correction and BJ damping, ${ }^{33}$ which is widely used for iron containing heme and non-heme system. ${ }^{34,35}$

A basis set benchmark study was performed for one of the P450 ${ }_{\text {BM} 3}$ variants, $\mathrm{X}-\mathrm{E} 12$ using two basis sets def2-SVP (denoted as B1) and def2-TZVP (denoted as B2), ${ }^{36}$ and two well established spin states for the iron in the Cpd I of P450, doublet spin state $(S=1 / 2)$ and quartet spin state $(S=3 / 2)$. 
Following the benchmark study, geometry optimizations were carried out for all the other variants using UB3LYP-D3BJ/def2-SVP. The ZPE were calculated with the same level of DFT functional and added to all the stationary points. The final energies were corrected at UB3LYPD3BJ/def2-TZVPP level. RIJCOSX approximation ${ }^{37}$ was used in all the QM calculations. In the QM/MM calculation in each mutant, several snapshots were calculated, and the averaged barrier was calculated using Equation 1.

175

$$
\Delta \mathrm{E}_{\mathrm{av}}^{\neq}=-\mathrm{RT} \ln \left(\frac{1}{n} \sum_{i=1}^{n} \exp \left(\frac{-\Delta E_{i}^{\neq}}{\mathrm{RT}}\right)\right)
$$

(Equation 1)

\section{RESULTS AND DISCUSSION}

\subsection{Origin of regio- and stereoselectivity}

\subsubsection{Binding of Arteminsinin in the P450}

In the catalytic cycle by eukaryotic P450, the electron transfer occurs from a FAD/FMN dependent NADPH-cytochrome P450 oxidoreductase (CPR) to P450 monooxygenase. FAD accepts electron from NADPH, while the FMN reduces P450. Generation of the active oxidant Cpd I in P450 requires activation of molecular oxygen by the reducing cofactor NADPH, followed by protonation at the distal oxygen of the superoxo intermediate, consecutive protonation of Compound $0(\mathrm{Cpd} 0)$, a ferric-hydroperoxo intermediate and leaving of a water molecule (Scheme 1). 

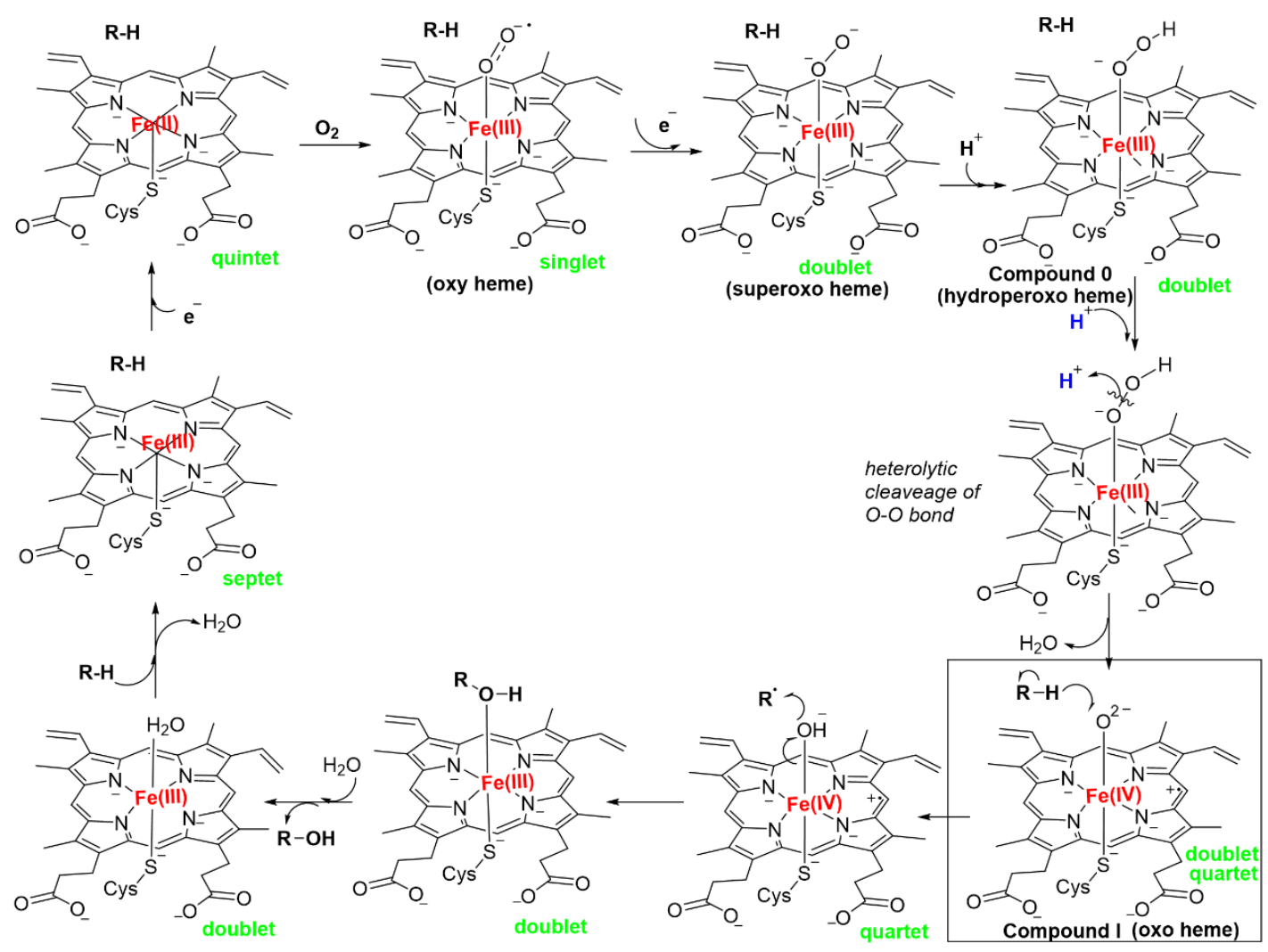

Scheme 1. Proposed mechanism for the P450-catalyzed hydroxylation of substrate R-H.

P450 ${ }_{\mathrm{BM} 3}$ (CYP102A1) is a self-sufficient fatty acid monooxygenase containing heme and

FAD/FMN domains. In the crystal structure of apo $\mathrm{P} 450_{\mathrm{BM} 3}$ from Bacillus megaterium formed a salt bridge with Lys224. The highly flexible loop is missing in the crystal structure of $\mathrm{P} 450_{\mathrm{BM}}$ in complex with a fatty acid substrate N-palmitoylglycine (PDB: $\left.1 \mathrm{JPZ}\right){ }^{38}$ The $\beta 1$ hairpin at the substrate entrance exhibits an open configuration and Arg47 on the hairpin formed a salt bridge with Glu352 (Supplementary information, Figure S1).

Starting from the F87A variant which showed minimal but detectable activity towards the probe molecules, an active FL\#62 template was identified using a fingerprinting method. ${ }^{39}$ FL\#62 converted the module compound artemisinin (Figure 1) to give a mixture of hydroxylated products. Majority of the products was C7 (S) enantiomer, and C7 (R) and C6a oxidized products were also observed. Further evolution of FL\#62 yielded three selective 
variants, X-E12, IV-H4 and II-H10, which gave 94\% selectivity for C6a oxidized product and $100 \%$ enantioselectivity for $\mathrm{C} 7(\mathrm{R})$ and $\mathrm{C} 7(\mathrm{~S})$ products. ${ }^{10}$ Two $\mathrm{P} 450$ variants that are only different in six amino acid positions showed a complete opposite stereoselectivity at position C7; additional four mutations resulted in unprecedented regioselectivity at position C6a.

(A)

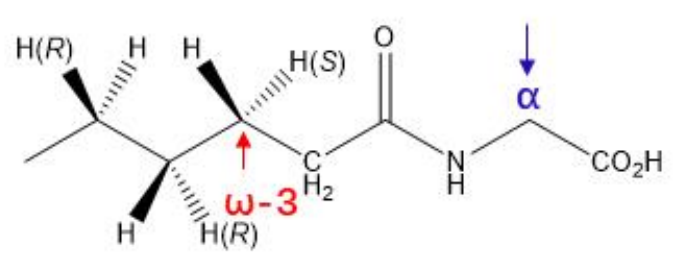

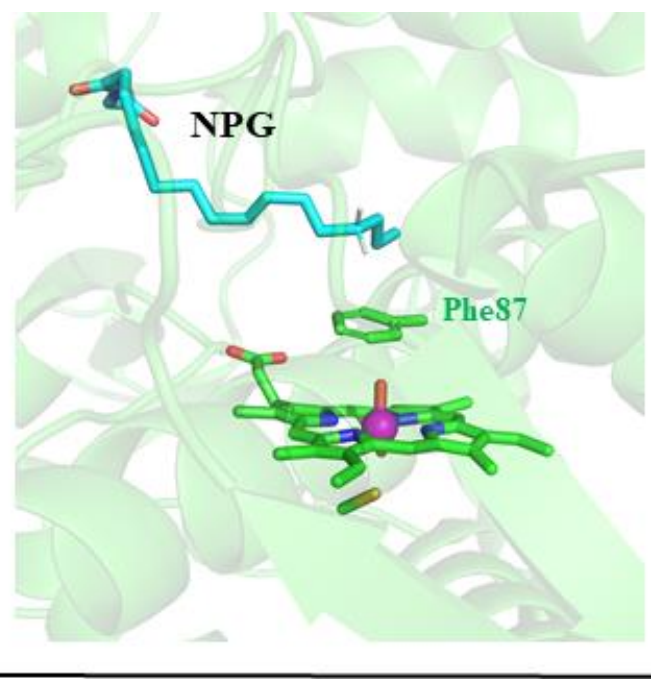

\section{Previous work:}

J. Am. Chem. Soc. 2016, 138, 837-845

J. Am. Chem. Soc. 2016, 138, 6786-6797
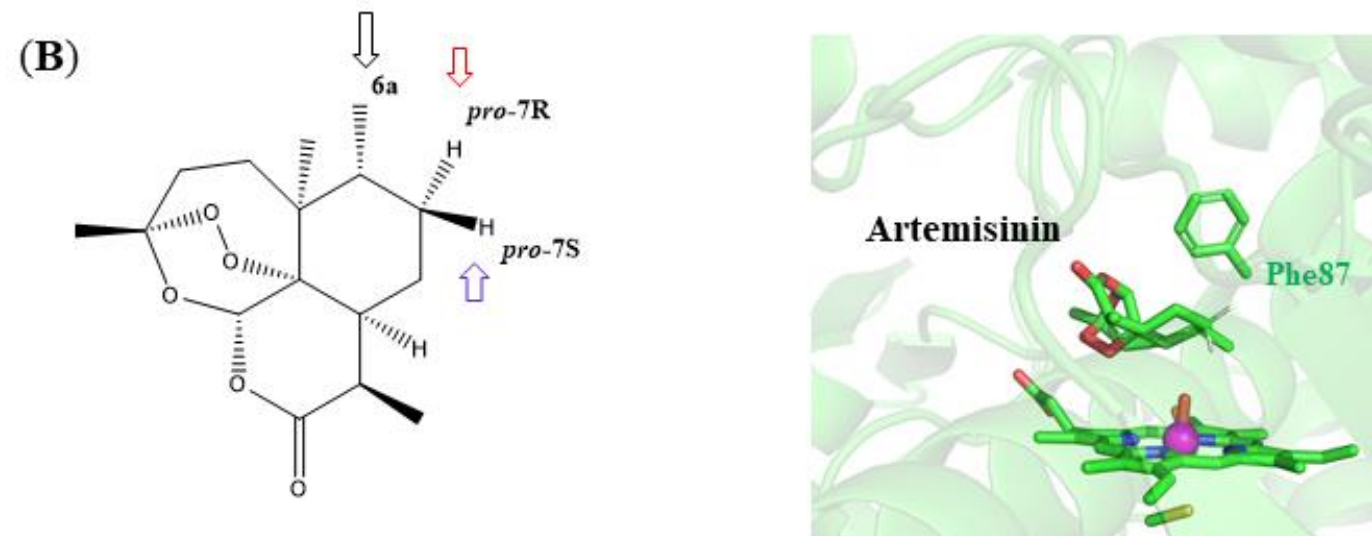

\section{Current work}

207

Figure 1. (A) Previous selectivity study on the fatty acid substrate NPG that mimics the native substrate of $\mathrm{P} 450_{\mathrm{BM} 3}$. (B) Current study is focused on the regio- and enantioselectivity of $\mathrm{P}_{450} \mathrm{BM}_{3}$ for cyclic terpene compounds, using artemisinin as a model molecule.

In order to understand the binding of arteminsinin in FL\#62, the ligand was first docked into the active site of the variant. The dominant docked poses showed preference to the prochiral $\mathrm{CH}_{2}$ that gives $\mathrm{C} 7(\mathrm{~S})$ enantiomer product (pro-C7(S)) (16 out of 50 docked poses), whereas 
215 few pro-C7(R) poses were also observed ( 2 out of 50 docked poses). In addition, predict

216 binding energy was $-5.31 \mathrm{kcal} / \mathrm{mol}$ for pro-C7(S) and $-4.55 \mathrm{kcal} / \mathrm{mol}$ for pro-C7(R), indicating

217 the pro-C7(S) is more stable than pro-C7(R). These are in agreement with the experimental

218 results that the $\mathrm{C} 7(\mathrm{~S})$ product is dominant by FL\#62. ${ }^{10} \mathrm{MD}$ simulations of FL\#62 in complex

219 with the pro-C7(S) or pro-C7(R) ligand (Figure S2-5) disclosed that Asp251 adjacent to the

220 FMN contacting loop formed a salt bridge with Lys224 (Figure S6A\&B). The hairpin Ala44-

221 Arg47 located at the substrate entrance exhibited a closed conformation in both complexes

222 (Figure 2). In contrast to the crystal structure of apo $\mathrm{P} 450_{\mathrm{BM} 3}$ where a salt bridge is observed

223 between Arg47 and Glu352 (Figure S1), ${ }^{14}$ such salt bridge was absent in the FL\#62-pro-

$224 \mathrm{C} 7(\mathrm{~S}) /(\mathrm{R})$ complex (Figure 2). 


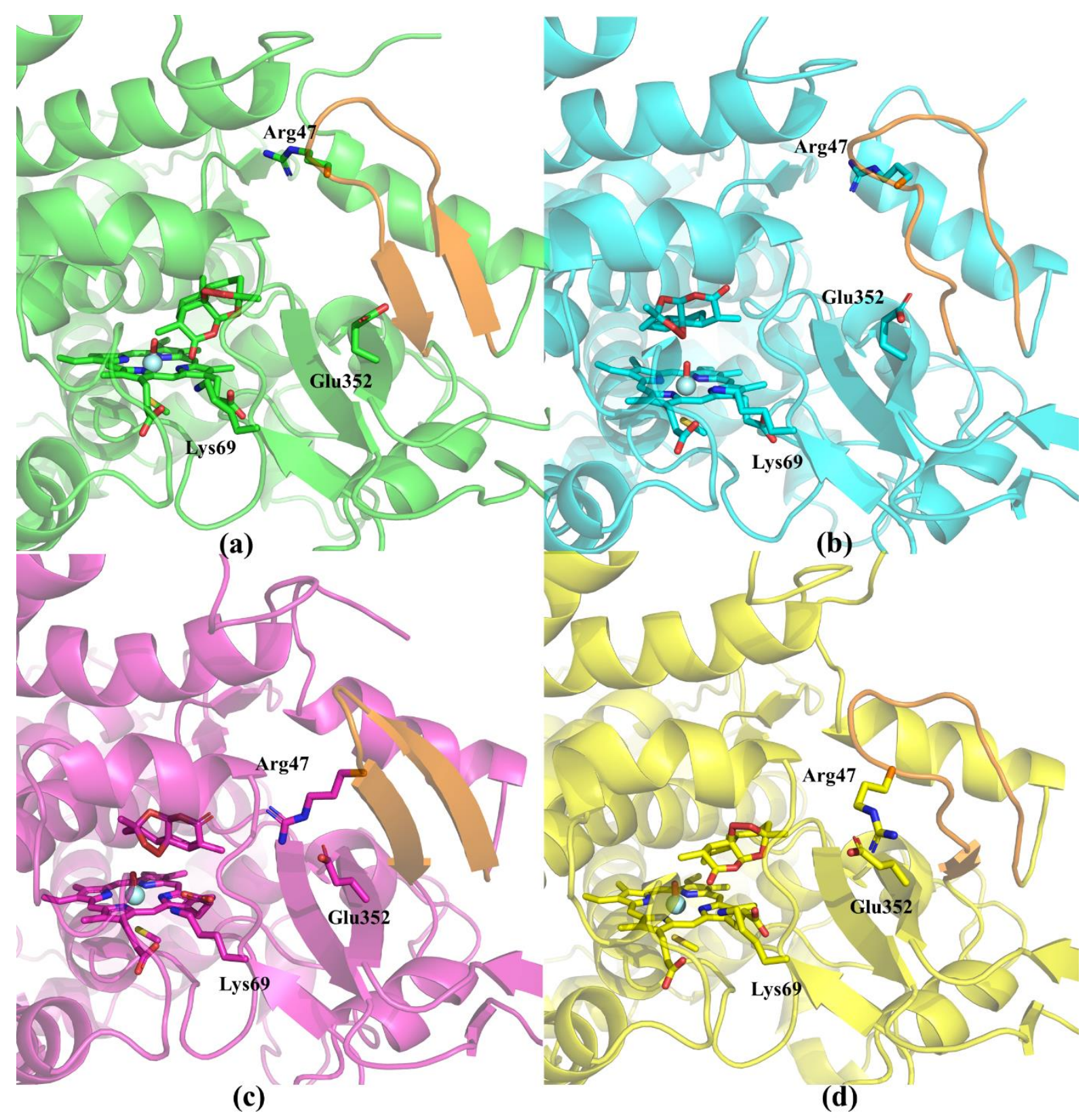




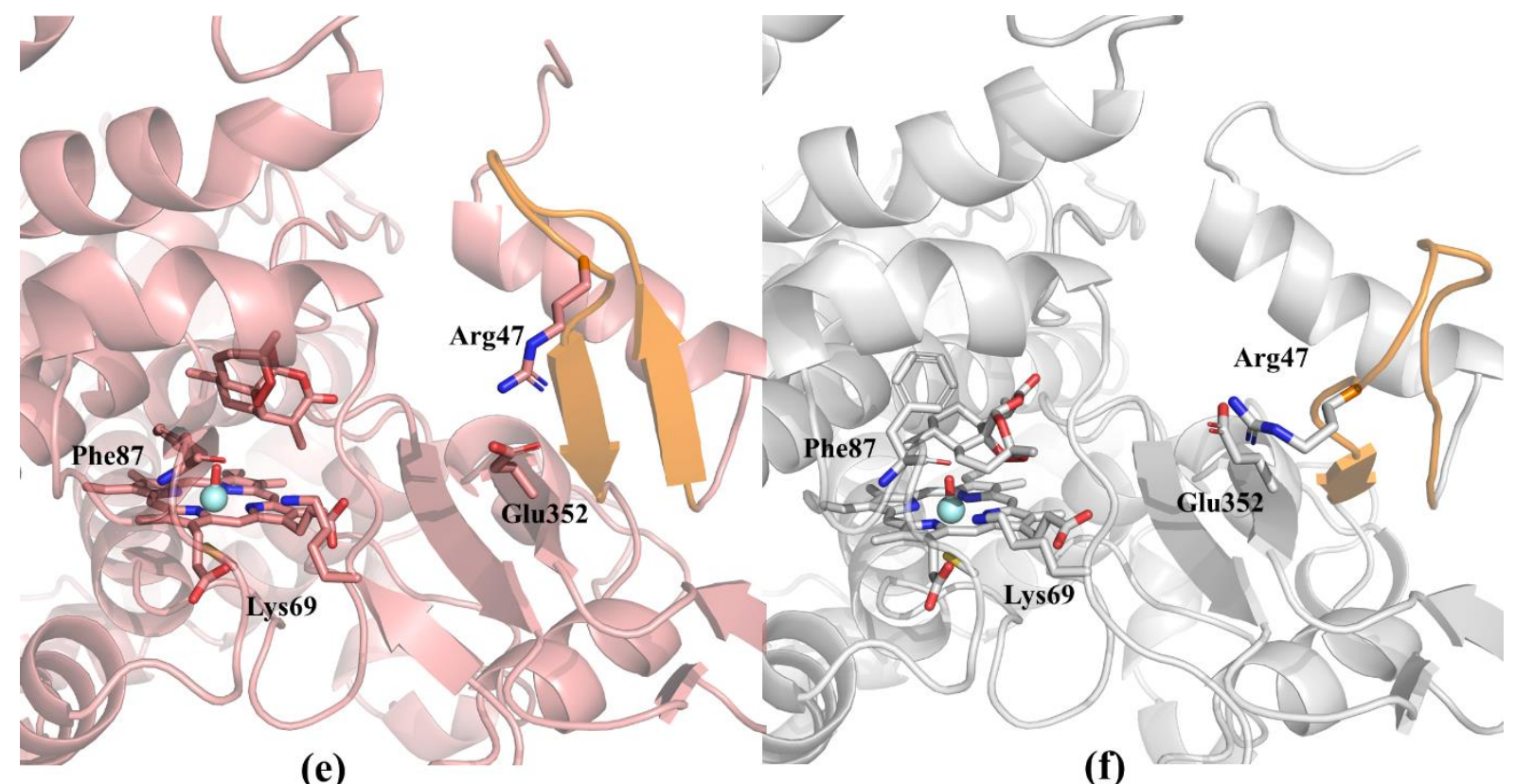

Figure 2. MD simulated structures $\mathrm{P} 450_{\mathrm{BM}} 3$ variants in complex with arteminsinin. (a) FL\#62 with pro-C7(S), (b) FL\#62 with pro-C7(R), (c) X-E12 with preference to the abstraction of the methyl H from C6a, (d) IV-H4 with pro-C7(S), (e) II-H10 with pro-C7(R) (Phe87 -in), (f) IIH10 with pro-C7(R) (Phe87 -out). The hairpin near the substrate entrance is shown in orange.

It should be noted that in FL\#62-pro-C7(S) complex, both propanoic acid carboxylate interact with Lys69 that is located at loop 69-73 near the substrate entrance. Lys69 was involved in the hydrogen bond with the substrate via C10 carbonyl group of the lactone. Interestingly, in the FL\#62-pro-C7(R) complex, Lys69 moved away from the substrate such that it only forms ionic bond with one of propanoic acid carboxylates, however, unlike the enzyme in presence of prooxygen, which may account for the low conversion toward the $\mathrm{C}(\mathrm{R})$ product compared to the C7(S) product. 


\subsection{C7(S) selectivity}

In the IV-H4 P450 ${ }_{\mathrm{BM} 3}$ variant, three additional mutations $\mathrm{A} 78 \mathrm{~S}, \mathrm{~S} 81 \mathrm{~V}$ and $\mathrm{V} 82 \mathrm{~A}$ were introduced in the active site of the FL\#62 variant. Selective hydroxylation at C7 with complete S-stereoselectivity was achieved by IV-H4. ${ }^{10}$ MD simulations (Figure S9) showed that the pro$\mathrm{C} 7(\mathrm{~S})$ hydrogen was consistently closer to the $\mathrm{Fe}(\mathrm{IV})=\mathrm{O}$ than pro-C7(R) hydrogen during the entire length of MD trajectory (Figure S10), in agreement with the experimental result that 7(S)-hydroxylated artemisinin is the preferred product by the mutant. ${ }^{10}$ Lys224 was located on the FMN contacting loop 240-250, and it formed a salt bridge with Asp251 in the crystal structure of apo $\mathrm{P} 450 \mathrm{BM}^{14}{ }^{14}$. The MD simulated structure of IV-H4 mutant in complex with proC7(S) artiminsinin showed that Lys 224 formed a salt bridge with Asp251 (Figure S6). In addition, a salt bridge was formed between Glu352 and Arg47 located at the hairpin Ala44Arg47, leading to a closed substrate entrance (Figure 2). Interestingly, this salt bridge was absent in the FL\#62-pro-C7(S) complex. Lys69 formed a hydrogen bond with the C10 carbonyl oxygen of substrate, locking the lactone of the substrate in the catalytic site such that the prochiral (S) hydrogen at $\mathrm{C} 7$ position was pushed toward the vicinity of $\mathrm{Fe}(\mathrm{IV})=\mathrm{O}$. The substrate was nested in a hydrophobic pocket composed of Leu75, Ala87, Ala328 and Leu437 (Figure 3). The mutations at positions 78, 81 and 82, may synergistically introduce additional flexibility of the loop adjacent to the $\beta^{\prime}$ helix, which caused Leu75 on the helix to form favourable hydrophobic interaction with the substrate, helping to correctly orientate the substrate to achieve the C7-(S) selectivity. 
(A)

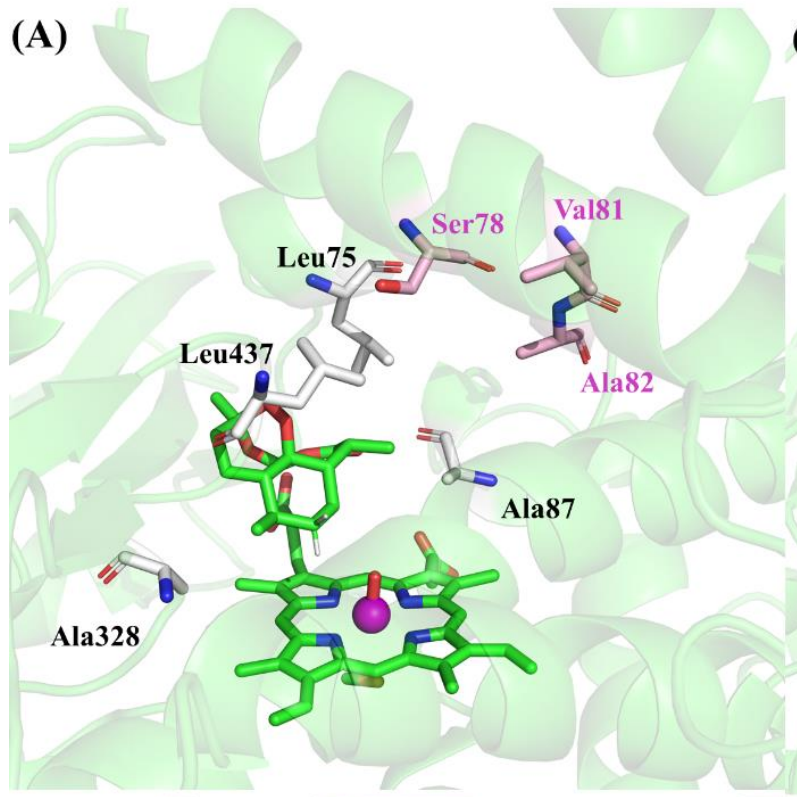

\section{(C)}

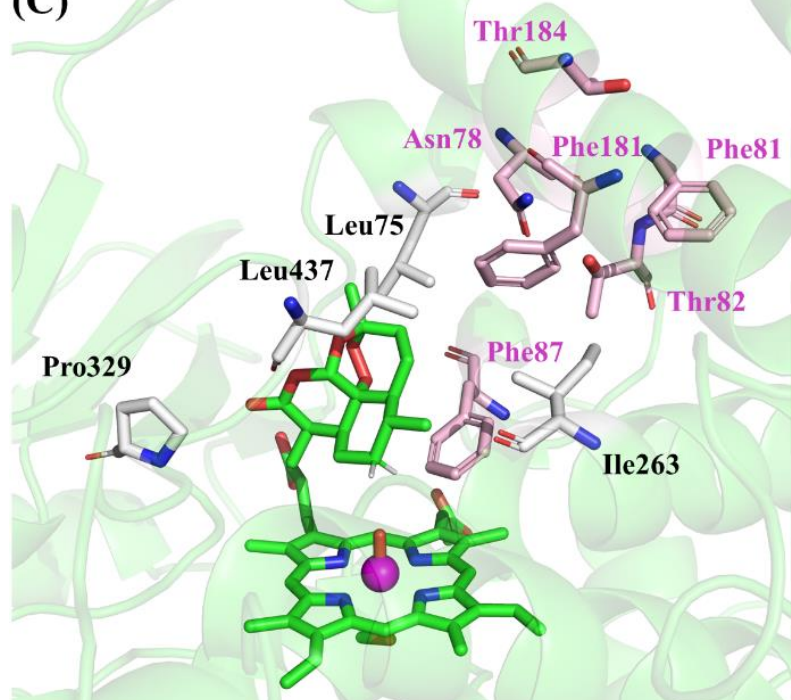

(B)

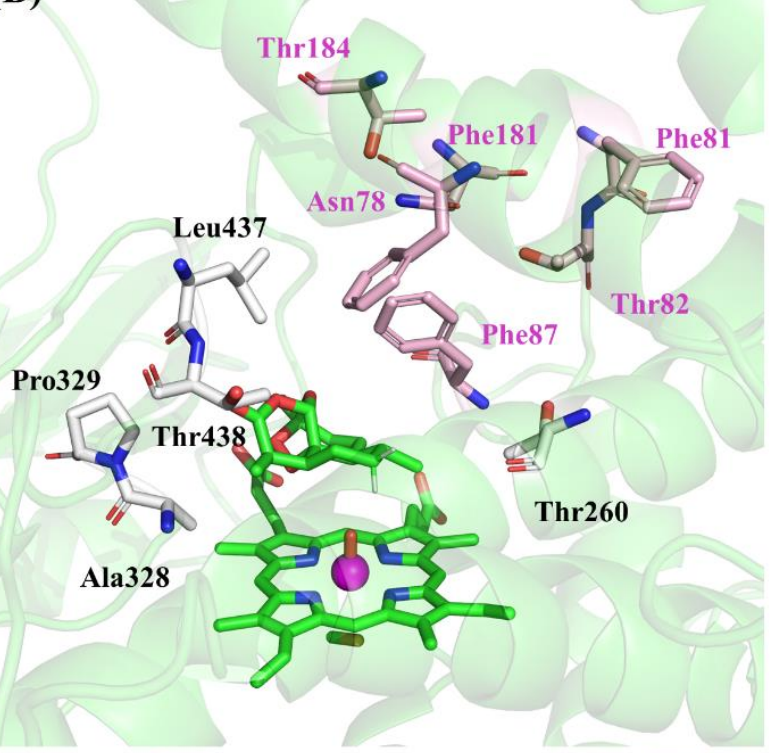

(D)

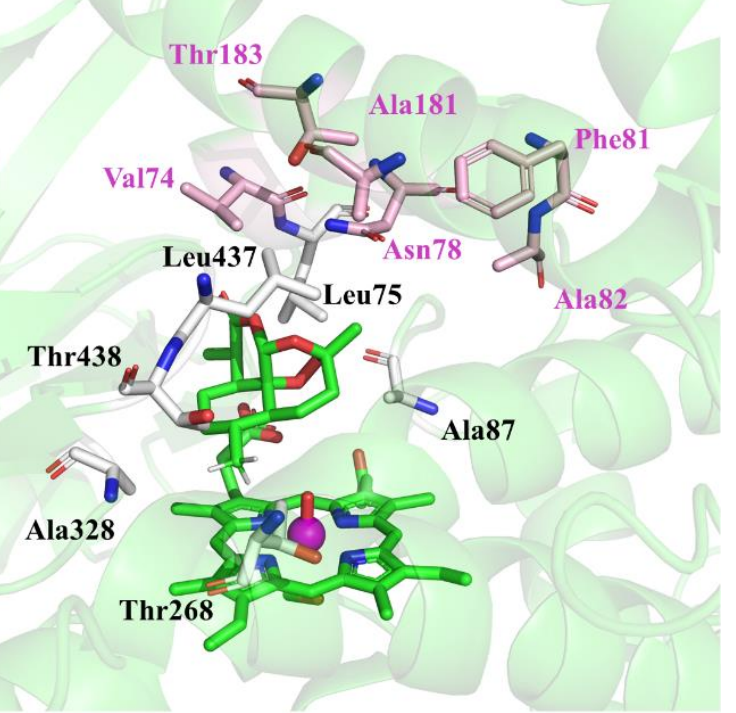

Figure 3. MD simulated structures of $\mathrm{P}_{450_{\mathrm{BM}} 3}$ variants in complex with arteminsinin. (A) IV-

(Phe87-in). (D) X-E12 with preference to the abstraction of the methyl H from C6a. The mutated residues in relation to the FL\#62 template are shown in pink.

\subsubsection{C7(R) selectivity}

271 Previous QM/MM studies suggested that Phe87 play an important role in controlling the (R)

272 stereoselectivity of oxidation reactions for fatty acid substrate. ${ }^{12}$ In the II-H10 variant, the small 
alanine at position 87 was mutated back into phenylanaline. In addition to $\mathrm{A} 87 \mathrm{~F}$, five mutations were introduced in the II-H10 variant compared to the FL\#62 template, namely, A78N, S81F, V82T, L181F, V184T, which gave hydroxylated product at C7 position with $100 \% \mathrm{R}$ selectivity. The MD simulations of the II-H10-pro-C7(R) complex (Figure S11) showed that the distance between the $\mathrm{Fe}=\mathrm{O}$ and pro- $\mathrm{C} 7(\mathrm{R})$ hydrogen were generally shorter than with $\mathrm{C} 7(\mathrm{~S})$ or C6a (Figure S12), in agreement with the experimentally observed exclusive R-enantiomer product. $^{10}$

MD simulations of II-H10 in complex with arteminsinin disclosed that Phe87 exhibited two representative conformations. One pointed away from the catalytic site (hereafter called Phe87out), and the other pointed inward the catalytic centre and resides between Cpd I and arteminsinin (hereafter called Phe87-in). In both conformations, Glu352 and Arg47 formed an ionic bond. The four mutations A78N, S81F, V82T, A87F located on the flexible loop adjacent to the $\beta$ ' helix may helped to orientate Phe87 appropriately in relation to the substrate and catalytic centre, while the mutation of the second sphere residues L181F and V184T on the F helix further stabilized the substrate binding by favourable $\mathrm{H}$-bond or hydrophobic interactions with the first-sphere residues.

The $\beta 1$ hairpin around the substrate entrance Ala44-Arg47 displayed an open conformation in the Phe87-out conformation, similar to the $\mathrm{P} 450_{\mathrm{BM} 3}$ in complex with a native fatty acid substrate analogue. ${ }^{38}$ Lys69 formed an ionic bond with the distal propionic carboxylate group of porphyrin ring and also formed a $\mathrm{H}$-bond with the backbone carbonyl of Phe87. Arteminsinin in the Phe87-out conformation is nested in a relatively compact hydrophobic pocket formed by Phe87, Thr260, Ala328, Pro329, Leu437 and Thr438 (Figure 3B). In contrast, in the Phe87-in conformation, the $\beta 1$ hairpin is closed. Leu437 pointed away from the binding pocket so that the hydrophobic pocket composed of Leu75, Ile263, Pro329 and Leu437 is enlarged (Figure 3C). Closing of the hairpin pushed the $\beta^{\prime}$ helix along with $\mathrm{F} / \mathrm{G}$ helix away 
from the catalytic centre, as a result, the substrate moved further away from the heme centre

allowing Phe87 to move toward the heme centre and position itself between the heme porphyrin ring and the substrate. It is also worth noting that a salt bridge was observed between Lys 224 and Asp251 near the FMN contacting loop in the Phe87-out conformation whereas this interaction is absent in the Phe87-in conformation (Figure 2).

Since both conformations was observed in the extensive MD simulations of II-H10 in complex with pro-C7(R) arteminsinin, both was considered in the subsequent QM/MM calculations in the study of C7(R) enantioselectivity. It was found that Phe87-out conformation displayed a lower energy barrier than Phe87-in conformation in the hydrogen abstraction from the pro-(R) hydrogen by heme $\mathrm{Fe}(\mathrm{IV})=\mathrm{O}$ (see section 3.2.3).

\subsubsection{C6a selectivity}

Similar to FL\#62, X-E12 contains a F87A mutation, which was suggested to broaden the substrate scope of $\mathrm{P} 450_{\mathrm{BM} 3}{ }^{40}$ In the X-E12 mutant, six additional mutations were introduced compared to FL\#62, namely, A74V, A78N, S81F, V82A, L181A and V184T and the selectivity toward C6a was increased significantly from $7 \%$ to $94 \%$. During the MD simulations the distance between $\mathrm{C} 6 \mathrm{a}$ and $\mathrm{Fe}=\mathrm{O}$ retained largely around $2.5 \AA$ (Figure S6). Mutating Ala74 on the $\beta$ ' helix into Val enabled favourable hydrophobic interaction with Leu437. Meanwhile, the replacement of the residues on the $\beta$ '-helix that was underpinned by the flexibility of the adjacent loop 69-73 reshaped a favourable hydrophobic pocket to accommodate the substrate. The $\beta 1$ hairpin Ala44-Arg47 at the mouth of the substrate entrance was closed up and a salt bridge was formed between Arg47 and Glu352 (Figure 2C). It should be noted that the salt bridge was also present in IV-H4-pro7(S) and II-H10-pro-C7(R) complexes, whereas it was absent in the FL\#62-pro-7(S)/(R) complex. Thus, maintaining the salt bridge between Arg47 and Glu352 caused $\beta^{\prime}$ helix to move closer to the substrate and would be important for achieving the selectivity at C6a or C7 of artemisinin. Closing the substrate entrance pushed the 
substrate further in the active site with the C6a positioned closer to the Cpd I oxidant. Further,

324 Thr268 on the distal H-helix, which was previously suggested to be important for the $\mathrm{O}_{2}$ binding and activation for the catalysis of fatty acid substrate, ${ }^{41}$ formed a hydrophobic interaction with the C6 methyl group of tricyclic terpene, so as to lock it in the active site

327 facilitating the subsequent oxidative reaction. As a result, artemisinin is nested in a hydrophobic site formed by Ala87, Thr268, Ala328, Leu437, Thr438 as well as Val74 and Leu75 located on at the $\beta$ ' helix (Figure 3D). Hence, altering the loop region 69-73 and the adjacent $\beta$ '-helix, as well as F-helix (181-190) that is in direct contact with the $\beta$ '-helix may modulate the substrate entrance and also reshape the catalytic pocket, and thus may further enhance the regioselectivity toward the C6a of arteminsinin (Figure 4).

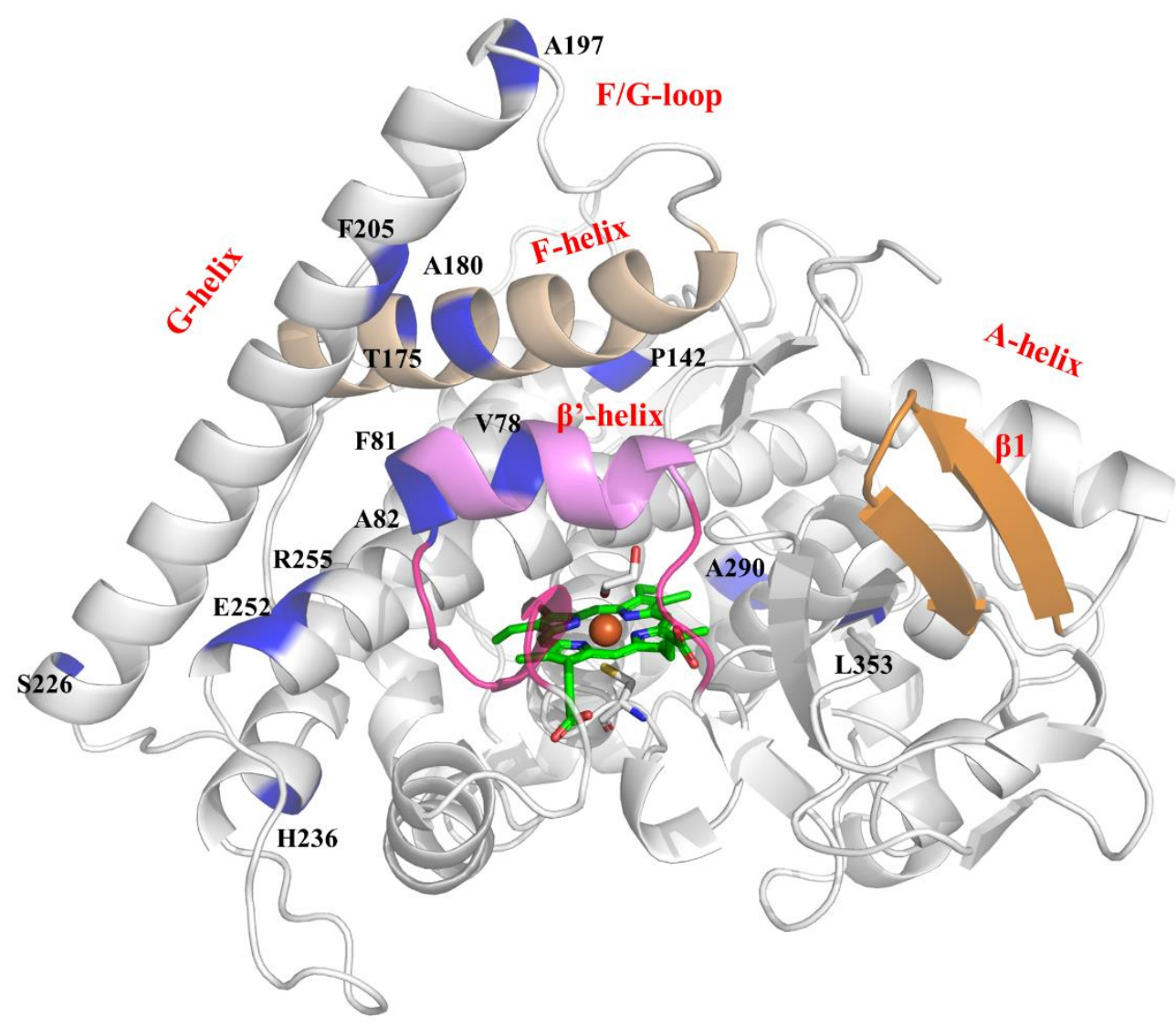

Figure 4. The crystal structure of $\mathrm{P} 450_{\mathrm{BM} 3}$ (PDB: $\left.1 \mathrm{BVY}\right) .{ }^{14}$ The heme group in the active site of $\mathrm{P} 450_{\mathrm{BM} 3}$ is shown in stick representation. The positions mutated in the FL\#62 template are shown in blue. The proposed hot spots from this research is shown in purple. 


\subsection{Origin of reactivity by $\mathrm{QM} / \mathrm{MM}$ calculations}

\subsubsection{C-H activation at C6a of arteminsinin}

Four representative structures from MD simulations of X-E12 in complex with the ligand were selected for QM/MM studies in order to investigate the effect of conformational sampling on the barrier of the rate limiting step of the reaction.

Among the four reaction profiles, the activation barrier from cluster 0 showed the lowest barrier of $22.1 \mathrm{kcal} / \mathrm{mol}$ (Supplementary information Table S1, Figure S16). An average barrier of $22.7 \mathrm{kcal} / \mathrm{mol}$ was obtained according to equation 1 (Figure 5).

A basis set benchmark study was performed for cluster 0 , the representative structure of X-E12 variant from MD simulations, which has the lowest barrier for the hydrogen abstraction. In addition to def2-SVP basis set (B1), geometry optimizations were also conducted using def2TZVP basis set (B2). The difference in the energy barrier using the two basis sets was less than $2 \mathrm{kcal} / \mathrm{mol}$ (Figure S16). The error was mainly attributed by the potential energy calculated at the two basis sets, while the ZPE at these basis sets were almost same (Table S2A \&B). Thus, energies obtained by geometry optimization using a double Zeta basis set (def2-SVP: B1) with a triple Zeta basis set (def2-TZVP: B2 or def2-TZVPP: B2') single point energy correction would give reaction energies as accurate as those calculated from full optimization using large def2-TZVP basis set (B2//B2).

Doublet $(S=1 / 2)$ and quartet $(S=3 / 2)$ spin states are the two plausible spin states of iron in $\mathrm{Cpd}$

I of heme enzymes and exhibit similar reactivity, ${ }^{42,47}$ so these two spin states were calculated in the benchmark study (Table S2). Our calculations showed that the two spin states were highly degenerated, with a barrier of $22.7 \mathrm{kcal} / \mathrm{mol}$ for $\mathrm{S}=1 / 2$ and $22.8 \mathrm{kcal} / \mathrm{mol}$ for $\mathrm{S}=3 / 2$ based on the energies of the geometries optimized with def2-TZVP (B2) basis set (Figure S17). Since 


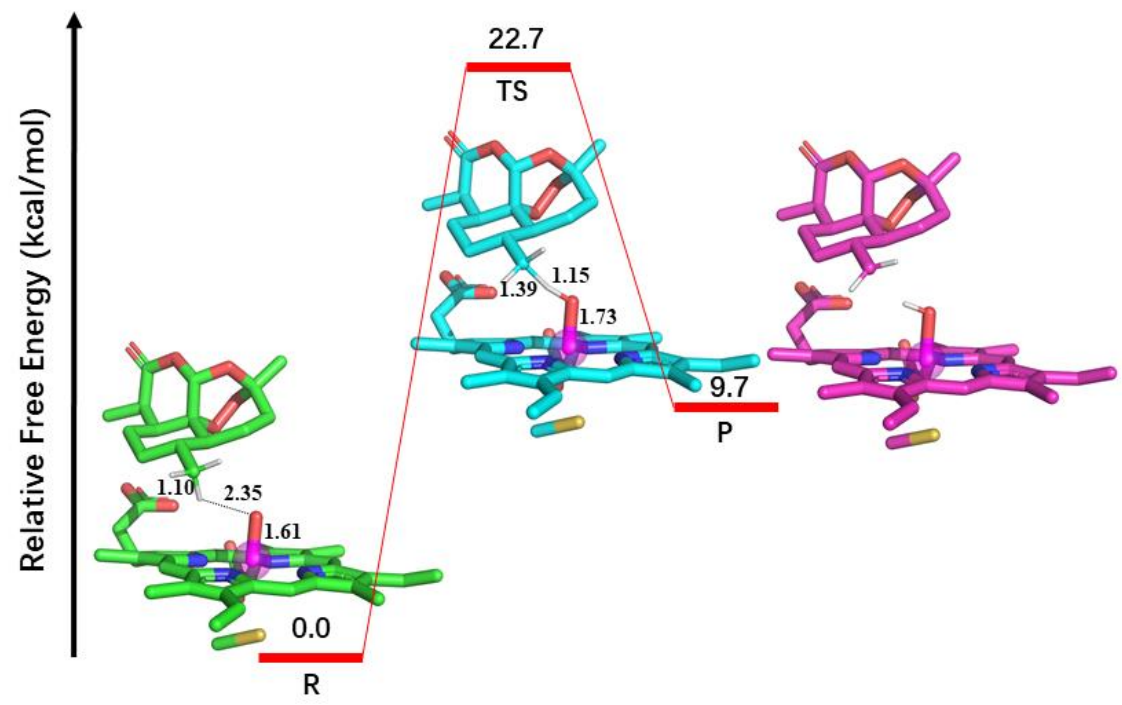

Figure 5 Free energy profile of hydrogen abstraction by X-E12. Four snapshots from cluster analysis were used here, and the energy here was averaged using Equation 1. The distance in this graph was from Cluster 0 .

In the optimized reactant of X-E12-arteminsinin (Figure 5), the distance between the $\mathrm{Fe}(\mathrm{IV})=\mathrm{O}$ and C6a was $3.13 \AA$. The hydrogen atom to be abstracted from the C6a methyl was $2.35 \AA$ away from the $\mathrm{Fe}(\mathrm{IV})=\mathrm{O}$ oxo in the $\mathrm{Cpd}$ I oxidant. The angle of hydrogen atom of the C6a methyl group approaching the $\mathrm{Fe}(\mathrm{IV})=\mathrm{O}(\mathrm{C} 6 \mathrm{a}-\mathrm{O}-\mathrm{Fe})$ was $120.3^{\circ}$ (Table S3), in agreement with previously research that suggested that the optimal angle for an approaching hydrogen atom to be abstracted for either aliphatic or aromatic hydroxylation is around $110-130^{\circ}$, which would provide a good orbital overlap and reduce the activation barrier. ${ }^{11}$ The optimized transition state (TS) showed $\mathrm{Fe}=\mathrm{O}$ bond increased from $1.61 \AA$ in the reactant to $1.73 \AA$ in the TS. The distance between the hydrogen to be transferred and C6a is increased from $1.10 \AA$ to1.39 and to $\mathrm{Fe}=\mathrm{O}$ oxygen is decreased from $2.35 \AA$ to $1.15 \AA$ (Table $\mathrm{S} 3$ ).

The hydrogen abstraction is followed by the rebound step, where the $\mathrm{Fe}(\mathrm{IV})-\mathrm{OH}$ intermediate generated form the hydrogen abstraction is rebounded to the substrate radical. The hydrogen 
379 abstraction has been shown to be rate-limiting step of the P450-catalyzed hydroxylation reaction. ${ }^{42-46}$ The rebound step calculations were run on two representative clusters $\mathrm{C} 1$ and C2 (Figure S18). The relative free energy profile shows that the barrier associated with the

382 rebound step is lower than that of the hydrogen abstraction step, indicating the hydrogen abstraction is the rate limiting step. This is in agreement with previous literature, ${ }^{43-46}$ so the later discussion is focused on the hydrogen abstraction, the rate limiting step of the P450catalyzed hydroxylation.

\subsubsection{C-H activation of artemisinin for C7 (S) selectivity}

The IV-H4 P450 ${ }_{\mathrm{BM} 3}$ variant showed an absolute regio- and enantioselectivity for $\mathrm{C} 7$ hydroxylation. ${ }^{10}$ The hydroxylation of $\mathrm{C} 7$ were studied on three representative cluster structures from the MD simulations of IV-H4 in complex with arteminsinin. Among them, cluster 3 showed the lowest barrier of $18.7 \mathrm{kcal} / \mathrm{mol}$ (Figure 6). The reaction profiles of abstraction of the prochiral hydrogen atom that gave a $\mathrm{C} 7(\mathrm{~S})$ hydroxylated was also investigated for the three representative cluster structures. The reaction barriers associated with the hydrogen abstraction leading to a $\mathrm{C} 7(\mathrm{R})$ hydroxylated product were consistently higher than those of the C7(S) by $5-10 \mathrm{kcal} / \mathrm{mol}$ (Figure 6, Figure S19). These results and in good agreement with the experimental findings that IV-H4 showed absolute (S) selectivity C7 position. ${ }^{10}$ The difference in the energy barriers associated with the abstraction of the prochiral hydrogen leading to the R/S hydroxylated products is similar to the previously reported barrier difference for the hydroxylation reaction at the $\omega$ or $\alpha \mathrm{CH}_{2}$ site of the fatty acid substrate catalyzed by $\mathrm{P} 450_{\mathrm{BM} 3}$ or $\mathrm{P} 450_{\mathrm{SP} \alpha}$, respectively. ${ }^{12,13}$ 


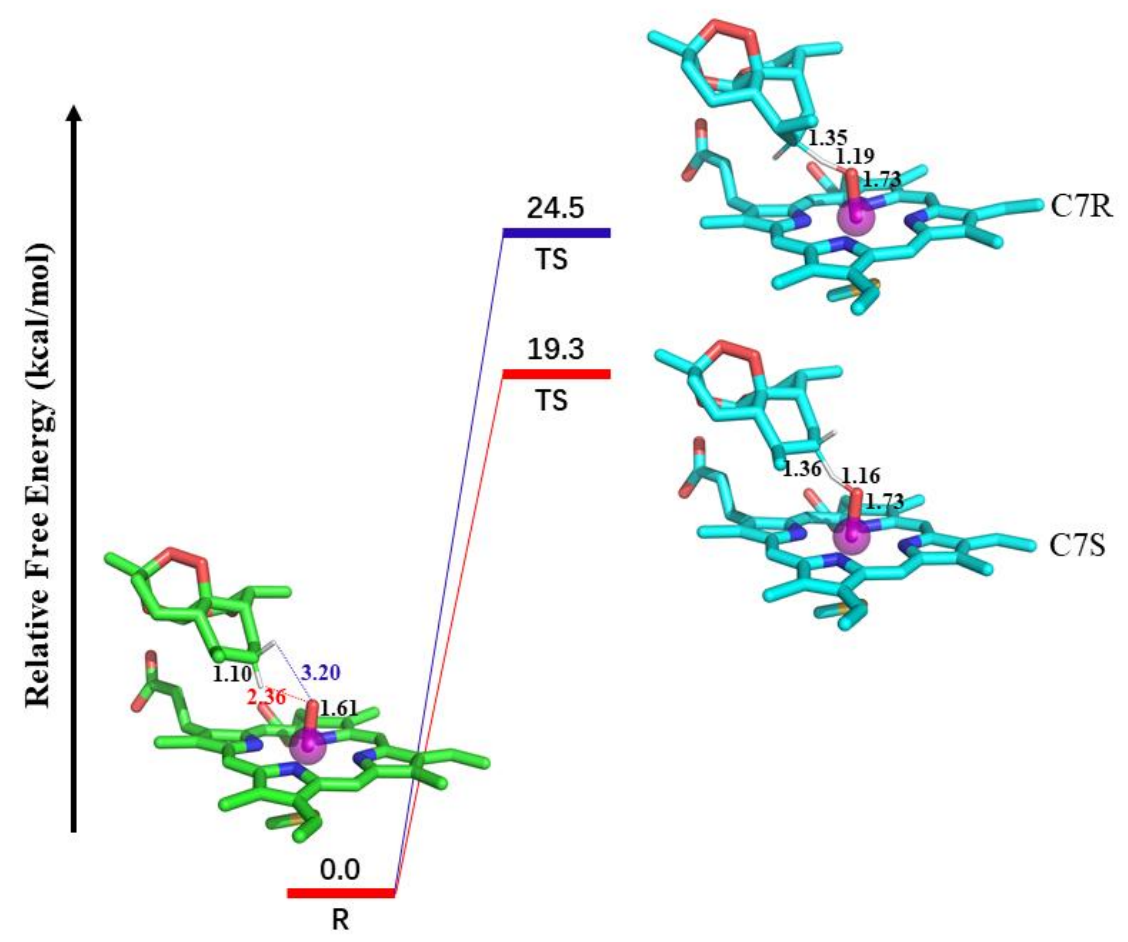

401 Figure 6 Free energy profile of hydrogen abstraction by IV-H4. 3 snapshots from cluster analysis were used here, and the energy here was averaged using Equation 1. The distance in this graph was from Cluster 3 .

404

405 In the QM/MM optimized reactant structure (Figure 7), $\mathrm{C} 7$ is $3.07 \AA$ away from $\mathrm{Fe}=\mathrm{O}$ oxo and 406 the angle formed by $\mathrm{C} 7-\mathrm{O}-\mathrm{Fe}$ is $124.2^{\circ}$ (Table S3). In the transition state, the bond length of O-H to be formed is $1.16 \AA$, and that of $\mathrm{C} 7-\mathrm{H}$ to be broken is $1.36 \AA$. In order to validate the transition state, nudged elastic band (NEB) calculations were conducted. It is shown that TS has correct connectivity to link to the reactant and TS-R indeed undergoes a longer path to the reactant than TS-S (Figure S20).

\subsubsection{C-H activation of artemisinin for C7 (R) selectivity}

413 Phe87 was previously suggested to be crucial for the substrate scope. ${ }^{12}$ Interestingly, in our 414 MD simulations of II-H10 in complex with arteminsinin, Phe87 adopted two distinct conformations. In the Phe87-out complex, Phe87 pointed away from the active site (Figure S11 

and the ligand. Comparison of the switching between Phe87-in/Phe87-out conformations (Figure S14) and the overall visiting frequency (Figure S15) from multiple MD replicas run started from these two poses showed the Phe87-in is slightly more stable than the Phe87-out conformation. The relative visiting frequency corresponds to an energy difference of 0.7 $\mathrm{kcal} / \mathrm{mol}$ (Figure 7). First the reaction profiles for both Phe87-out orientations were studied based on two representative structures from cluster analysis of MD simulations. For the Phe87out complex, the average activation barrier calculated using Equation 1 for the hydrogen abstraction was around $18.9 \mathrm{kcal} / \mathrm{mol}$ (Figure 7). The distance between $\mathrm{C} 7$ and $\mathrm{Fe}=\mathrm{O}(3.12 \AA)$ is comparable to the other $\mathrm{P}_{450} 0_{\mathrm{BM} 3}$ variants complexes (Table S3), however, the angle formed by $\mathrm{Fe}=\mathrm{O}-\mathrm{C} 7$ was $163.3^{\circ}$, much larger than those observed in the other two variants. In the transition state, $\mathrm{O}-\mathrm{H}$ and $\mathrm{C}-\mathrm{H}$ were $1.17 \AA$ and $1.34 \AA$, respectively.

QM/MM calculation were then conducted for Phe87-in, also starting from two representative structures from the cluster analysis of the MD simulations. Cluster 1 showed slightly lower activation barrier $24.6 \mathrm{kcal} / \mathrm{mol}$ than cluster 2 with a reaction energy of $8.0 \mathrm{kcal} / \mathrm{mol}$ (Figure S21). Since Phe87 is located in the proximity of Cpd I, the effect of including the residue in QM region was also investigated. Little difference in the reaction barrier was observed when Phe87 was included in the QM region (denoted as L-QM). In the reactant, the distance between $\mathrm{C} 7$ and the $\mathrm{Fe}=\mathrm{O}$ oxo was $3.44 \AA$ (Table S3) distance is larger than $\mathrm{X}$-E12-arteminsinin with C6a preference, or IV-H4-arteminsinin with $\mathrm{C} 7(\mathrm{~S})$ preference. Interestingly, similar to the Phe87-out complex, the angle formed by $\mathrm{Fe}=\mathrm{O}-\mathrm{C} 7$ is also large being $154.5^{\circ}$, both notably larger than those observed in the other two variants that give the C6 or C7(R) selectivity. In addition, the transition state showed a longer $\mathrm{OH}$ distance of $1.20 \AA$ and shorter $\mathrm{CH}$ distance of $1.34 \AA$ compared to the other two variants. 
440 The reaction profiles of II-H10 based on the two Phe87-out and Phe87-in conformations were

441

442

443

444

445

446

447

448

449

450

451

452

453

454

455

456

compared (Figure 7). The former showed lower activation barrier $(18.9 \mathrm{kcal} / \mathrm{mol})$ than the latter (25.0 kcal/mol). It should be noted that Phe87 in the crystal structure of $\mathrm{P}^{450_{\mathrm{BM} 3}}$ in complex with a fatty acid substrate N-Palmitoylglycine (NPG), ${ }^{38}$ adopts an similar orientation as Phe87in, also nested between the Cpd I and the fatty acid. Thus, the preference of Phe87-out over Phe87-in for the $\mathrm{C} 7(\mathrm{R})$ enantioselectivity suggests the different binding pocket requirement for the native fatty acid substrate and bulky cyclic terpene substrate such as artemisinin. The flexible loop (Phe81-Glu93) adjacent to $\beta$ ' helix needs to adopt an appropriate conformation so as to position Phe87 in favour of the substrate binding and subsequent selective hydroxylation.

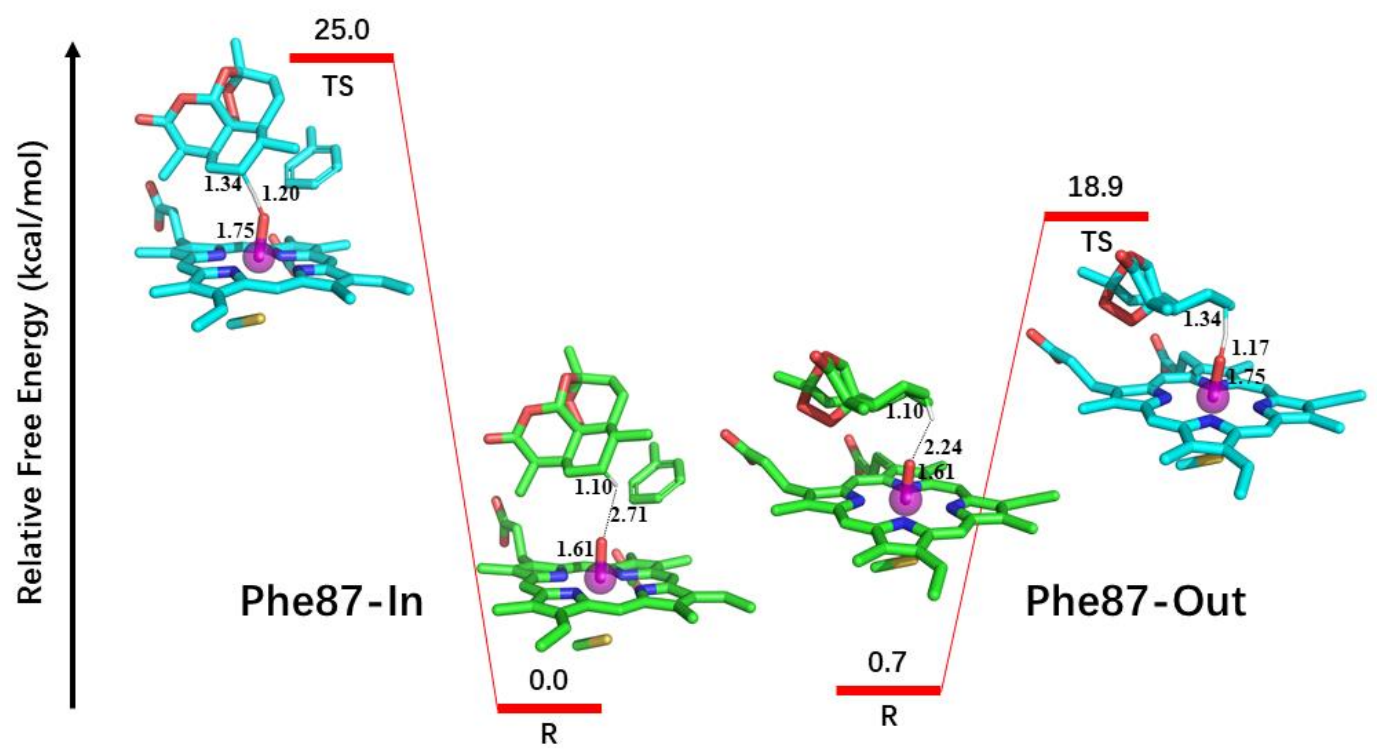

Figure 7 Free energy profile of hydrogen abstraction by II-H10 from two different poses Phe87-in and Phe87-out.

\subsection{Correlation between $\mathrm{OH}$ bond lengths and reaction barriers}

QM/MM calculations were conducted for the representative cluster structures from MD simulations for three $\mathrm{P} 450_{\mathrm{BM} 3}$-variants using $\mathrm{QM} / \mathrm{MM}$ calculations. The $\mathrm{O}-\mathrm{H}$ distance between 
the $\mathrm{H}$ to be abstracted from arteminsinin and the iron Oxo of Compound I)in the QM/MM

458

459

460

461

462

463

464

465

466

467

468

469

470

471

472

473

474 optimized reactants from different clusters spanned a good range, therefore, we were interested to investigate if there is correlation between the $\mathrm{O}-\mathrm{H}$ distances and the reaction barriers for hydrogen abstraction at different positions of artemisninin. The activation energies were plotted as a function of the $\mathrm{O}-\mathrm{H}$ distances in the QM/MM optimized reactant structures (Table S1). Strikingly, a positive correlation is observed between the activation barriers and $\mathrm{O}-\mathrm{H}$ distances, for the hydrogen abstraction at C6a by X-E12 variant, or C7(S) by IV-H4 and C7(R) by II-H10 (Figure 8). This indicates that the representative structure with shortest $\mathrm{O}-\mathrm{H}$ distance is associated with lower reaction barrier, and therefore can be selected for the subsequent reaction mechanism study without the need to conduct complete free energy profile calculations for many representative cluster structures. This would be valuable in enzyme engineering of $\mathrm{P} 450_{\mathrm{BM} 3}$, since it would be possible to predict the reactivity of the designed variants for hydroxylation at specific C-H site to be activated, based on the QM/MM optimized reaction coordinates of the selected representative structures from MD simulations.

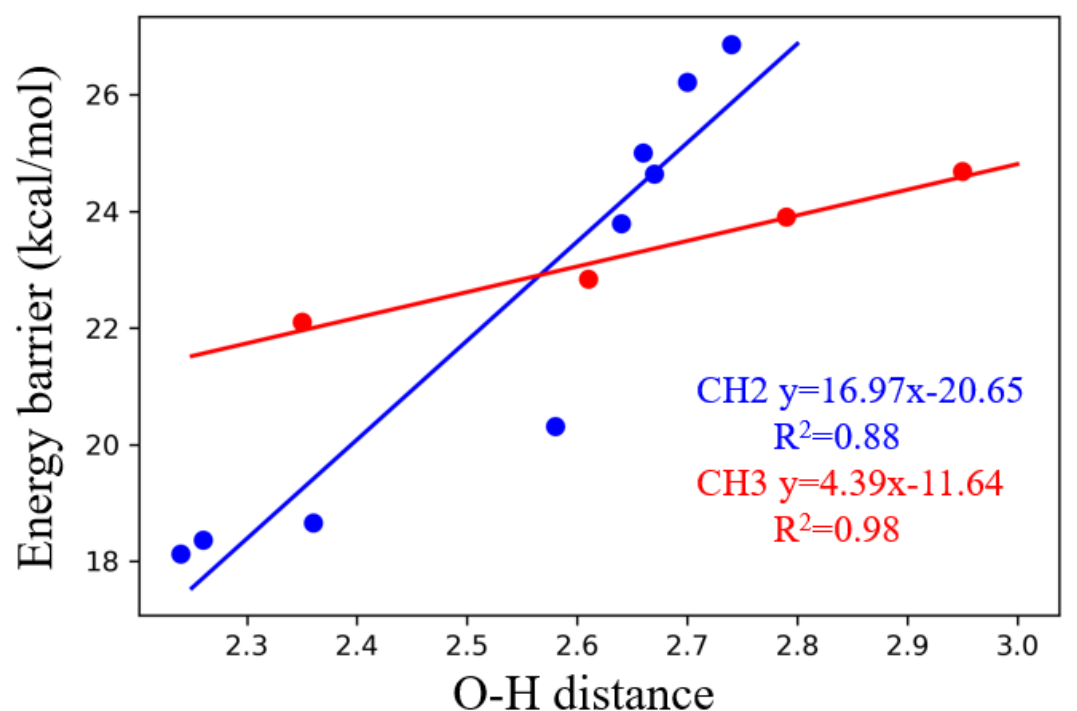

Figure 8. Correlation of free energy barriers with the reaction coordinate (i.e. the $\mathrm{OH}$ distance corresponding to the abstraction of $\mathrm{H}$ from the terpenoid to the iron Oxo of Compound $\mathrm{I}$ ) in 
QM/MM optimized reactant structures. $\mathrm{H}$ abstraction from $\mathrm{C}^{6} \mathrm{a} \mathrm{CH}_{3}$ in the $\mathrm{XE}-12$ variant are shown in red. The hydrogen abstraction from the prochiral $\mathrm{CH}_{2}$ of $\mathrm{C} 7 \mathrm{in} \mathrm{IV}-\mathrm{H} 4$ and II-H10 variants are shown in blue.

\section{CONCLUSIONS}

Elucidating the selectivity of C-H activation at various positions in drug molecules by $\mathrm{P} 450$ is crucial for understanding drug metabolism mechanism as well as rationally engineering the enzyme as biocatalysts for synthesis of high-value products that are difficult to be accessible via chemical synthesis routes. The site selectivity of native fatty acid substrate by $\mathrm{P} 450_{\mathrm{BM} 3}$ has been studied by QM/MM studies, however, little is known for the binding and selectivity for non-native complex bulky natural products such as terpenoids. Here, molecular docking, molecular dynamics simulations and $\mathrm{QM} / \mathrm{MM}$ calculations were conducted for $\mathrm{P} 450_{\mathrm{BM}}$ catalyzed hydroxylation, using arteminsinin as a model compound, in order to understand the selectivity and the $\mathrm{C}-\mathrm{H}$ activation at the $\mathrm{C} 6 \mathrm{a}$ and $\mathrm{C} 7$ positions of the substrate.

Three P450 ${ }_{\mathrm{BM} 3}$ variants, $\mathrm{X}-\mathrm{E} 12, \mathrm{IV}-\mathrm{H} 4$ and II-H10 that were reported to convert artemisinin with high regio- or enantioselectivities at $\mathrm{C} 6 \mathrm{a}$ or $\mathrm{C} 7$ positions were studied. Comparison of the MD simulated structures of these variants and their template FL\#62 disclosed remarkable displacement of the $\beta$ ' helix with the subtle difference in the mutations among them. Different interactions around the substrate binding pocket and substrate entrance were observed. The selectivity of the variants was attributed by the few different mutations in the three variants that reshaped the binding pocket, leading to favourable hydrophobic pocket to accommodate the substrate. Lys69 at the substrate entrance formed a favourable hydrogen bond with $\mathrm{C} 10$ of the lactone in IV-H4, whereas this additional hydrogen bond was absent in other two variants. The $\beta 1$ hairpin at the substrate entrance displayed an open conformation, however, it was closed in other X-E12 and II-H10 variants. Therefore, we propose altering the $\beta$ ' helix and its 
500

501

502

503

504

505

506

507

508

509

510

511

512

513

514

515

516

517 charge.

518 AUTHOR INFORMATION

519 Corresponding Author

520 Correspondence and request for materials should be addressed to M.H. m.huang@qub.ac.uk

adjacent secondary structures including the two adjacent loops and F-helix would modulate the substrate entrance and binding.

The activation barrier can be used to estimate the catalytic efficiency of the variants. The reactivity of the $\mathrm{C}-\mathrm{H}$ activation at $\mathrm{C} 6 \mathrm{a}$ and $\mathrm{C} 7$ positions of artemisinin was evaluated by QM/MM calculations, by estimating the activation energy barriers associated with the hydrogen abstraction from the $\mathrm{C} 6$ a methyl group or from the prochiral $\mathrm{CH}_{2}$ hydrogen atoms at $\mathrm{C} 7$ to $\mathrm{Fe}=\mathrm{O}$. Different representative structures obtained from MD simulations were used for the subsequent QM/MM calculation. A clear correlation was observed between the activation barriers and the distances between the $\mathrm{Fe}=\mathrm{O}$ and the hydrogen to be abstracted, indicating the $\mathrm{OH}$ distance in the $\mathrm{QM} / \mathrm{MM}$ optimized reactant would serve as a facile indicator on the reactivity of the enzyme for $\mathrm{C}-\mathrm{H}$ activation. The results reported in this research would provide valuable insight for rationally engineering of P450 for selective hydroxylation of complex cyclic molecules.

\section{ASSOCIATED CONTENT}

\section{Supplementary Information}

The supplementary Information is attached separately in PDF format and is available free of 
$\mathrm{CH}$ and WS conducted the experiments. MH supervised the project. All authors read and approved the manuscript.

\section{Notes}

The authors declare no competing financial interest.

\section{ACKNOWLEDGMENT}

The authors acknowledge the financial support from INVEST NI Research and Development Programme, part financed by the European Regional Development Fund under the Investment for Growth and Jobs programme 2014-2020. This work was supported by the Natural Science Foundation of China (No. 21736002, and the National Key Research and Development Program of China (2018YFA0901800). We are grateful for the computing resources from QUB high performance computing Tier2 computing resource funded by EPSRC (EP/T022175).

\section{REFERENCES}

1. P. R. Ortiz de Montellano, Chem Rev, 2010, 110, 932-948.

2. J. A. McIntosh, C. C. Farwell and F. H. Arnold, Curr Opin Chem Biol, 2014, 19, 126-134.

3. W. Sun, H. Xue, H. Liu, B. Lv, Y. Yu, Y. Wang, M. Huang and C. Li, Acs Catal, 2020, 10, 42534260.

4. $\quad$ S. Kille, F. E. Zilly, J. P. Acevedo and M. T. Reetz, Nat. Chem., 2011, 3, 738-743.

5. A. Li, C. G. Acevedo-Rocha, L. D'Amore, J. Chen, Y. Peng, M. Garcia-Borràs, C. Gao, J. Zhu, H. Rickerby, S. Osuna, J. Zhou and M. T. Reetz, Angew. Chem., Int. Ed., 2020, 59, 12499-12505.

6. C. G. Acevedo-Rocha, C. G. Gamble, R. Lonsdale, A. Li, N. Nett, S. Hoebenreich, J. B. Lingnau, C. Wirtz, C. Fares, H. Hinrichs, A. Deege, A. J. Mulholland, Y. Nov, D. Leys, K. J. McLean, A. W. Munro and M. T. Reetz, Acs Catal, 2018, 8, 3395-3410.

7. J. Wang, Y. Zhang, H. Liu, Y. Shang, L. Zhou, P. Wei, W.-B. Yin, Z. Deng, X. Qu and Q. Zhou, Nat. Commun., 2019, 10, 3378.

8. H. Xiao, Y. Zhang and M. Wang, Trends Biotechnol., 2019, 37, 618-631.

9. X. Zhang, Y. Peng, J. Zhao, Q. Li, X. Yu, C. G. Acevedo-Rocha and A. Li, Bioresour. Bioprocess., 2020, 7, 2.

10. K. Zhang, B. M. Shafer, M. D. Demars, H. A. Stern and R. Fasan, J. Am. Chem. Soc., 2012, 134, 18695-18704.

11. R. Lonsdale, K. T. Houghton, J. Żurek, C. M. Bathelt, N. Foloppe, M. J. de Groot, J. N. Harvey and A. J. Mulholland, J. Am. Chem. Soc., 2013, 135, 8001-8015.

12. K. D. Dubey, B. Wang and S. Shaik, J. Am. Chem. Soc., 2016, 138, 837-845.

13. R. Ramanan, K. D. Dubey, B. Wang, D. Mandal and S. Shaik, J. Am. Chem. Soc., 2016, 138, 6786-6797.

14. I. F. Sevrioukova, H. Li, H. Zhang, J. A. Peterson and T. L. Poulos, PNAS, 1999, 96, 1863. 
15. K. Shahrokh, A. Orendt, G. S. Yost and T. E. Cheatham III, J. Comput. Chem., 2012, 33, 119133.

16. D. A. Case, R. M. Betz, D. S. Cerutti, T. E. Cheatham, III, T. A. Darden, R. E. Duke, T. J. Giese, H. Gohlke, A. W. Goetz, N. Homeyer, S. Izadi, P. Janowski, J. Kaus, A. Kovalenko, T. S. Lee, S. LeGrand, P. Li, C., Lin, T. Luchko, R. Luo, B. Madej, D. Mermelstein, K. M. Merz, G. Monard, H. Nguyen, H. T. Nguyen, I., Omelyan, A. Onufriev, D. R. Roe, A. Roitberg, C. Sagui, C. L. Simmerling, W. M. Botello-Smith, J. Swails, R. C. Walker, J. Wang, R. M. Wolf, X. Wu, L. Xiao and P. A. Kollman, 2016, University of California, San Francisco.

17. M. J. Frisch, G. W. Trucks, H. B. Schlegel, G. E. Scuseria, M. A. Robb, J. R. Cheeseman, G. Scalmani, V. Barone, G. A. Petersson, H. Nakatsuji, X. Li, M. Caricato, A. V. Marenich, J. Bloino, B. G. Janesko, R. Gomperts, B. Mennucci, H. P. Hratchian, J. V. Ortiz, A. F. Izmaylov, J. L. Sonnenberg, Williams, F. Ding, F. Lipparini, F. Egidi, J. Goings, B. Peng, A. Petrone, T. Henderson, D. Ranasinghe, V. G. Zakrzewski, J. Gao, N. Rega, G. Zheng, W. Liang, M. Hada, M. Ehara, K. Toyota, R. Fukuda, J. Hasegawa, M. Ishida, T. Nakajima, Y. Honda, O. Kitao, H. Nakai, T. Vreven, K. Throssell, J. A. Montgomery Jr., J. E. Peralta, F. Ogliaro, M. J. Bearpark, J. J. Heyd, E. N. Brothers, K. N. Kudin, V. N. Staroverov, T. A. Keith, R. Kobayashi, J. Normand, K. Raghavachari, A. P. Rendell, J. C. Burant, S. S. Iyengar, J. Tomasi, M. Cossi, J. M. Millam, M. Klene, C. Adamo, R. Cammi, J. W. Ochterski, R. L. Martin, K. Morokuma, O. Farkas, J. B. Foresman and D. J. Fox, Journal, 2016.

18. W. L. Jorgensen, J. Chandrasekhar, J. D. Madura, R. W. Impey and M. L. Klein, J. Chem. Phys., 1983, 79, 926-935.

19. J. A. Izaguirre, D. P. Catarello, J. M. Wozniak and R. D. Skeel, J. Chem. Phys., 2001, 114, 20902098.

20. H. J. C. Berendsen, J. P. M. Postma, W. F. van Gunsteren, A. DiNola and J. R. Haak, J. Chem. Phys., 1984, 81, 3684-3690.

21. J. P. Ryckaert, G. Ciccotti and H. J. C. Berendsen, J. Comput. Phys., 1977, 23, 327-341.

22. T. Darden, D. York and L. Pedersen, J. Chem. Phys., 1993, 98, 10089-10092.

23. D. R. Roe and T. E. Cheatham, J Chem Theory Comput, 2013, 9, 3084-3095.

24. W. Humphrey, A. Dalke and K. Schulten, J. Mol. Graph., 1996, 14, 33-38.

25. P. Sherwood, A. H. de Vries, M. F. Guest, G. Schreckenbach, C. R. A. Catlow, S. A. French, A. A. Sokol, S. T. Bromley, W. Thiel, A. J. Turner, S. Billeter, F. Terstegen, S. Thiel, J. Kendrick, S. C. Rogers, J. Casci, M. Watson, F. King, E. Karlsen, M. Sjøvoll, A. Fahmi, A. Schäfer and C. Lennartz, J. Mol. Struct. THEOCHEM, 2003, 632, 1-28.

26. F. Neese, WIRES Comput Mol Sci, 2012, 2, 73-78.

27. W. Smith and T. R. Forester, J. Mol. Graph., 1996, 14, 136-141.

28. D. Bakowies and W. Thiel, J. Phys. Chem., 1996, 100, 10580-10594.

29. U. C. Singh and P. A. Kollman, J. Comput. Chem., 1986, 7, 718-730.

30. J. Kästner, J. M. Carr, T. W. Keal, W. Thiel, A. Wander and P. Sherwood, J. Phys. Chem. A, 2009, 113, 11856-11865.

31. C. Lee, W. Yang and R. G. Parr, Phys. Rev. B, 1988, 37, 785-789.

32. B. Miehlich, A. Savin, H. Stoll and H. Preuss, Chem. Phys. Lett., 1989, 157, 200-206.

33. S. Grimme, S. Ehrlich and L. Goerigk, J. Comput. Chem., 2011, 32, 1456-1465.

34. A. Altun, D. Kumar, F. Neese and W. Thiel, J. Phys. Chem. A, 2008, 112, 12904-12910.

35. H. Chen, J. Song, W. Lai, W. Wu and S. Shaik, J Chem Theory Comput, 2010, 6, 940-953.

36. F. Weigend and R. Ahlrichs, Phys. Chem. Chem. Phys., 2005, 7, 3297-3305.

37. F. Neese, F. Wennmohs, A. Hansen and U. Becker, Chem. Phys., 2009, 356, 98-109.

38. D. C. Haines, D. R. Tomchick, M. Machius and J. A. Peterson, Biochemistry, 2001, 40, 1345613465.

39. K. Zhang, S. El Damaty and R. Fasan, J. Am. Chem. Soc., 2011, 133, 3242-3245.

40. C. J. C. Whitehouse, S. G. Bell and L.-L. Wong, Chem. Soc. Rev., 2012, 41, 1218-1260.

41. H. Yeom, S. G. Sligar, H. Li, T. L. Poulos and A. J. Fulco, Biochemistry, 1995, 34, 14733-14740. 
608 42. S. Shaik, D. Kumar, S. P. de Visser, A. Altun and W. Thiel, Chem Rev, 2005, 105, 2279-2328.

609 43. T. Kamachi and K. Yoshizawa, J. Am. Chem. Soc., 2003, 125, 4652-4661.

610 44. D. Kumar, S. P. de Visser, P. K. Sharma, S. Cohen and S. Shaik, J. Am. Chem. Soc., 2004, 126,

611 1907-1920.

612 45. I. Viciano and S. Martí, J. Phys. Chem. B, 2016, 120, 3331-3343.

613 46. W. Lai, H. Chen, S. Cohen and S. Shaik, J. Phys. Chem. Lett., 2011, 2, 2229-2235.

614 47. S. Shaik, S. Cohen, Y. Wang, H. Chen, D. Kumar and W. Thiel, Chem Rev, 2010, 110, 949-1017. 